\title{
Strategi Dan Manajemen Dakwah Majelis Tafsir Al Qur'an Melalui MTA TV Surakarta
}

\author{
Silvia Riskha Fabriar ${ }^{1}$, Kurnia Muhajarah ${ }^{2}$ \\ ${ }^{1,2}$ UIN Walisongo Semarang \\ Email: silviariskhaf@walisongo.ac.id, kurniamuhajarah@walisongo.ac.id
}

\begin{tabular}{l}
\hline Article Info \\
\hline Article history: \\
Received 15 Februari2021 \\
Accepted 15 April 2021 \\
Published 22 Juli 2021 \\
Page : 124 - 135 \\
\hline
\end{tabular}

\section{Keyword:}

Strategi, Manajemen Dakwah, Majelis Tafsir al-Qur'an, MTA TV

\begin{abstract}
Da'wah can be done with various strategies according to the state of mad'u. Management in the organization is structured in such a way that da'wah activities run well and according to purpose. The Qur'an Tafsir Council (MTA) is one of the da'wah institutions that carry out its da'wah with various methods, one of which is through television media among other da'wah media. MTA TV presents various da'wah programs in accordance with the vision of the MTA institution. The purpose of this study is to see how the MTA propaganda strategy through television is also side by side with other media. The author uses a qualitative descriptive research method. The findings of this study indicate that MTA through MTA TV can carry out their da'wah effectively because they are able to reach a wider audience. MTA $T V$ is also able to adapt to the times so that this channel can survive, in addition to utilizing social networks that are in great demand by the public. However, on the other hand, the audience of listeners is still limited among Muslims who are members of this da'wah institution and the variety of programs is not so diverse.
\end{abstract}

Dakwah dapat dilakukan dengan berbagai strategi sesuai dengan keadaan mad'u. Manajemen dalam organisasi pun disusun sedemikian rupa agar aktivitas dakwah berjalan dengan baik dan sesuai tujuan. Majelis Tafsir Al Qur'an (MTA) merupakan salah satu lembaga dakwah yang melakukan dakwahnya dengan berbagai macam metode, salah satu diantaranya melalui media televisi diantara media dakwah lainnya. MTA TV menyajikan berbagai program dakwah sesuai dengan visi lembaga MTA. Tujuan penelitian ini adalah untuk melihat bagaimana strategi dakwah MTA melalui televisi yang juga berdampingan dengan media lainnya. Penulis menggunakan metode penelitian deskriptif kualitatif. Temuan penelitian ini menunjukkan bahwa MTA melalui MTA TV dapat melakukan dakwahnya dengan efektif karena mampu menjangkau khalayak yang lebih luas. MTA TV juga mampu beradaptasi dengan perkembangan zaman sehingga channel ini bisa bertahan selain dengan memanfaatkan jejaring sosial yang banyak diminati masyarakat. Namun, di sisi lain khalayak pendengarnya masih terbatas di kalangan muslim yang tergabung dengan lembaga dakwah ini dan variasi program yang belum begitu beragam. .

Copyright (C) 2021 Journal Of Islamic Management.

\section{Editorial Office:}

Program Studi Manajemen Dakwah, Fakultas Dakwah dan Komunikasi, UIN Sunan Ampel Surabaya.

Jl. Ahmad Yani 117 Surabaya, Jawa Timur, Indonesia.

Email: jim@uinsby.ac.id 


\section{Pendahuluan}

Aktivitas dakwah mensyaratkan adanya interaksi antara da'i dan mad'u dalam sebuah proses komunikasi. Dari proses inilah nilai-nilai Islam yang bersifat sakral ditransformasikan ke dalam masyarakat sehingga konsep rahmatan lil'alamin bisa terealisasi. Aktivitas dakwah diharapkan dapat memberi kontribusi positif di tengah berbagai ketimpangan, kerusakan, kecurangan, dan berbagai tindakan tercela lain yang disebabkan terkikisnya nilai-nilai agama dalam diri manusia. ${ }^{1}$ Oleh sebab itu, dai hendaknya memilih cara dan metode yang tepat agar dakwah menjadi aktual, faktual, dan konstekstual menjadi bagian dari strategi dari kegiatan dakwah itu sendiri. ${ }^{2}$

Kemajuan teknologi informasi telah mengantarkan dunia menjadi kampung global. Interaksi antar budaya yang semula terhalang sekat geografis menjadi tak terhindarkan. Aktualisasi peran dakwah setiap muslim menjadi terbuka, yaitu dengan memanfaatkan multimedia sebagai wahana dakwah. Dakwah dengan memanfaatkan berbagai media massa merupakan jawaban bagi masyarakat dengan kondisi dan tatanan seperti sekarang. Salah satu organisasi dakwah yang melihat peluang ini dan memanfaatkan media massa untuk kegiatan dakwahnya adalah Majelis Tafsir Al Qur'an (MTA) Surakarta.

Majelis Tafsir Al Qur'an (MTA) merupakan sebuah lembaga pendidikan dan dakwah Islamiyah yang berkedudukan

\footnotetext{
${ }^{1}$ Faisal Ismail, Dakwah Ditengah Persoalan Budaya dan Politik. (Jakarta: Kurnia Kalam Semesta. 2001), hal. 3
}

di Surakarta. MTA didirikan oleh Ustadz Abdullah Thufail Saputra pada pada tanggal 19 September 1972 dengan tujuan untuk mengajak umat Islam kembali ke AlQur'an. ${ }^{3}$ Pendirian MTA bertujuan untuk menyelenggarakan kegiatan dakwah dalam bentuk pengajian rutin mempelajari tafsir Al Quran Hadits Nabi Muhammad SAW, kegiatan di bidang pendidikan, baik formal maupun non formal, dan kegiatan sosial kemanusiaan, MTA pun merambah dalam bidang penerbitan, komunikasi, dan informasi, sebab penggunaan media massa memungkinkan pesan dakwah yang disampaikan dapat diterima oleh sejumlah besar orang yang tersebar di banyak tempat, anonim dan heterogen. Adapun salah satu media massa yang dipakai MTA untuk mengembangkan dakwahnya yaitu MTA TV Surakarta.

Televisi mempunyai daya tarik yang sangat kuat dalam masyarakat, karena sifatnya yang audiovisual. Meskipun ada peluang besar bagi televisi untuk dimanfaatkan sebagai media dakwah, namun ada sebuah fenomena yang perlu dipertimbangkan yaitu ada kecenderungan masyarakat yang mulai meninggalkan televisi karena muncul pesaing baru yaitu media internet yang semakin berkembang pesat. Namun demikian, bukan berarti bahwa dakwah menggunakan media televisi tidak ada manfaatnya karena jika melihat kekuatan (terutama gambar hidupnya dan dalam hal kedekatannya dengan kehidupan sehari-hari) yang dimilikinya, maka masih ada kesempatan untuk merebut perhatian masyarakat untuk kembali pada televisi. Permasalahannya. adalah bagaimana caranya mengemas pesan dakwah yang bisa menjadi media

\footnotetext{
2 Munzier Suparta dan Harjani Hefni, Metode Dakwah, (Jakarta: Prenada Media. 2003), hal. xii ${ }^{3}$ https://mta.or.id/profil/, diakses 25 Juni 2021
} 
yang menarik sebagaimana sebelum muncul dan berkembangnya internet.

Dakwah MTA dengan memanfaatkan ruang publik melalui media massa pasti menemui berbagai tantangan yang menuntut MTA untuk memiliki dan menerapkan strategi yang tepat dalam rangka memenangkan persaingan dan mengembangkan aktivitas dakwahnya. Dengan demikian, penelitian ini bertujuan untuk mengetahui bagaimana strategi dan manajemen yang diterapkan MTA TV sebagai perpanjangan tangan dari lembaga MTA.

\section{Kajian Pustaka}

\section{Strategi Dakwah}

Strategi adalah rencana atau cara atau langkah untuk mencapai suatu tujuan yang sudah ditetapkan. untuk mencapai tujuan, strategi tidak hanya sebagai cara yang menunjukkan jalan, tetapi harus mampu menunjukkan bagaimana taktik atau teknik yang harus dijalankan. Menurut Mudrajat Kuncoro, strategi adalah pola sasaran, tujuan, dan, kebijakan umum untuk mencapai tujuan yang sudah ditentukan. ${ }^{4}$ Strategi yang digunakan oleh suatu organisasi atau lembaga ditentukan oleh tujuan yang hendak dicapai dan kondisi yang ingin diwujudkan.

Strategi komunikasi (dakwah) adalah suatu rencana yang disusun sedemikian

\footnotetext{
${ }^{4}$ Mudrajad Kuncoro, Strategi :Bagaimana Meraih Keunggulan Kompetitif, (Jakarta: Erlangga, 2005), hal 1.

5 Helena Olii, Reportase Radio, (Jakarta: Indeks Kelompok Gramedia. 2006), hal. 22

${ }^{6}$ Onong Uchjana Effendi, IImu Komunikasi Teori Dan Praktek. (Bandung: PT. Remaja Rosdakarya, 2006), hal. 32
}

rupa agar pesan-pesan yang disampaikan bisa diterima, dimengerti, dan diikuti oleh komunikan (mad'u). ${ }^{5}$ Dengan demikian, strategi komunikasi (dakwah) bisa sewaktu-waktu berubah bergantung pada situasi dan kondisi yang sedang dihadapi. ${ }^{6}$

Strategi dakwah merupakan cara, teknik, taktik yang digunakan untuk melakukan aktivitas dakwah. Hakikat dakwah adalah program pelengkap yang meliputi semua pengetahuan yang dibutuhkan manusia untuk memberi penjelasan tentang tujuan hidup serta mampu membedakan mana yang haq dan mana yang bathil. ${ }^{7}$

Penerapan strategi dakwah harus memperhatikan beberapa hal, antara lain asas filosofi, yang membicarakan tentang hal yang berkaitan dengan tujuan yang akan dicapai dalam berdakwah; asas psikologi, asas yang berkaitan dengan kondisi kejiawaan manusia; dan asas sosiologi, yang membahas terkait dengan situasi dan kondisi sasaran dakwah. ${ }^{8}$

\section{Manajemen Dakwah}

Manajemen merupakan proses yang berkesinambungan dalam membuat suatu perencanaan, pengorganisasian, pengendalian dan pengarahan dengan memanfaatkan semua potensi sumber daya

7 Asep Muhiddin, Dakwah dalam Perspektif AlQur'an, (Cet. I; Bandung: Pustaka Setia, 2002), hal. 7

8 Novi Maria Ulfah, Strategi dan Manajemen Dakwah Lembaga Dakwah Islam Indonesia (LDII) Kecamtan Tugu Kota Semarang, (Jurnal IImu Dakwah, Vol 35, No 2, 2015), hal. 209 
yang tersedia untuk tujuan bersama. ${ }^{9}$ Semua tahap ini harus dilakukan dengan sistematis agar aktivitas yang direncanakan di awal sesuai dengan tujuan akhir.

Pelaksanaan dakwah berkaitan dengan beberapa unsur dakwah. Antara satu unsur dengan lainnya harus saling mendukung agar dakwah bisa efektif dan efesien. Seiring tuntutan zaman, manajemen sangat diperlukan untuk menopang kegiatan dakwah. Apabila dakwah dilakukan dengan menerapkan prinsip-prinsip manajemen, maka akan terwujud dakwah yang profesional dan berhasil dalam kehidupan masyarakat.

Rosyad Shaleh mendefiniskan manajemen dakwah sebagai proses perencanaan tugas, mengelompokkan tugas, menghimpun dan menempatkan para tenaga pelaksana dalam kelompok tugas dan menggerakkan ke arah pencapaian tujuan dakwah. ${ }^{10}$ Langkahlangkah teknis yang telah direncanakan dengan baik itu dilakukan dalam rangka membangun sumber daya manusia dalam upayanya menuju kehidupan yang diridhai Allah.

Dakwah di era ini tidak bisa lagi dilakukan hanya dengan cara konvensional, tetapi harus bisa mengikuti kondisi zaman, kondisi masyarakat yang terus mengalami perubahan. Dakwah bisa dilakukan dengan berbagai media massa, seperti radio, televisi, film, bahkan internet. Dakwah bisa disajikan secara audio,

9 Andy Dermawan, Manajemen Dakwah Kontemporer Di Kawasan Perkampungan (Studi Pada Kelompok Pengajian Asmaul Husna, Potorono, Banguntapan, Bantul, DIY), (Jurnal MD, Edisi Januari-Juni 2016), hal. 1 visual, maupun audio visual. Perkembangan modern dakwah ditandai dengan pemanfaatan informasi dan teknologi dalam rangka memaksimalkan proses aktivitas dakwah agar sampai kepada masyarakat $\left(\operatorname{mad}^{6} u\right)$,

\section{Metode Penelitian}

Metode penelitian yang digunakan dalam tulisan ini adalah deskriptif kualitatif. Metode kualitatif adalah tatacara penelitian yang menghasilkan data deskriptif berupa kata-kata tertulis atau lisan dari orang-orang dan perilaku yang dapat diamati. ${ }^{11}$ Penelitian deskriptif kualiatatif merupakan metode yang memanfaatkan data yang bukan berupa angka-angka (kualitatif) dan dijabarkan secara deskriptif. Data diperoleh melalui kepustakaan dan dokumen online seperti website MTA dan MTA TV, serta jejaring sosial MTA TV.

\section{Hasil dan Pembahasan}

Secara resmi MTA didaftarkan sebagai badan hukum dalam bentuk yayasan dengan akta notaris R. Soegondo Notodisoerjo Notaris di Surakarta nomor 23 tahun 1974. Kemudian Yayasan MTA didaftarkan kembali dengan akta notaris Budi Yojantiningrum, SH, Notaris di Karanganyar, nomor 01 tanggal 6 September 2006, dan disahkan oleh Menkumham dengan Keputusan Menteri No. C-2510.HT.01.02 TH 2006, yang

\footnotetext{
10 A. Rosyad Shaleh, Manajemen Dakwah Islam (Jakarta: Bulan Bintang, 1993), hal. 123.

${ }^{11}$ Lexy Moleong, Metodologi Penelitian Kuliatatif (Bandung: Remaja Rosdakarya, 2010), hal. 4
} 
ditetapkan tanggal 03 November 2006 dan tercatat dalam Berita Negara tanggal 27 Februari 2007 No. $17 .{ }^{12}$

Aktivitas dakwah MTA berkembang sampai ke berbagai kota dan provinsi di Indonesia. Struktur kelembagaan MTA terdiri dari Pusat, Perwakilan, dan Cabang. MTA Pusat berkedudukan di Surakarta, perwakilan berkedudukan di kabupaten/kota, dan cabang berkedudukan di tingkat kecamatan. Perkembangan MTA terjadi karena jama'ah yang mengikuti pengajian baik di MTA pusat atau di daerah masing-masing membentuk kelompok pengajian. Setelah kelompok tersebut menjadi besar, mereka mengajukan permohonan ke MTA pusat agar dikirim guru pengajar, sehingga kelompok-kelompok pengajian tersebut menjadi cabang-cabang baru. Dengan demikian, banyak bermunculan cabang baru.

Tujuan didirikannya MTA adalah untuk menyelenggarakan kegiatan dakwah dalam bentuk pengajian rutin mempelajari Tafsir Al Qur'an yang bersumber dari kitab-kitab Tafsir Al Qur'an karya para mufassir dan mempelajari Hadits Nabi Muhammad SAW yang bersumber dari kitab-kitab hadits, menyelenggarakan kegiatan bidang pendidikan, baik formal ataupun non formal, menyelenggarakan kegiatan sosial kemanusiaan, seperti donor darah, evakuasi korban bencana, serta bakti sosial kemanusiaan lainnya baik diselenggarakan secara mandiri maupun bekerjasama dengan Pemerintah, TNI dan

12 https://mta.or.id/profil/, diakses 25 Juni 2021

${ }^{13} \mathrm{https://mta.or.id/profil/,} \mathrm{diakses} 25$ Juni 2021
Polri. MTA merupakan organisasi yang independen, tidak terikat dengan organisasi massa manapun dan partai politik apapun. ${ }^{13}$

Keberadaan cabang di berbagai daerah tersebut yang menginspirasi MTA utnuk melakukan dakwahnya melalui media massa, agar jamaah yang berada di daerahdaerah tersebut bisa mengikuti pengajian pada waktu yang sama.

Pada awalnya karena terjadi kerusakan pada satelit Telkom 1, siaran MTA TV migrasi sementara ke Telkom 3s. Pada awal tahun ini pindah lagi ke Satelit Merah Putih (Telkom 4) bersama dengan channel lain seperti Temanggung TV, Ruai TV, HCBN Indonesia, dan lain sebagainya.14 Selain pindah satelit dari Telkom 3S ke Telkom 4, MTA TV juga pindah frekuensi. Di Telkom 4 atau satelit merah putih ini frekuensi MTA TV solo menempati transponder dengan frekuensi 3896 polaritas horisontal dan simbol rate $3000 .{ }^{15}$ Format siaran MTA TV sudah memenuhi standar DVB-S dengan kualias siaran MPEG-2/ SD.

Tabel 1. Kualifikasi Siaran

\begin{tabular}{ll}
\hline Frekuensi MTATV & \\
\hline Satelit & Telkom 4 at $108.0^{\circ} \mathrm{E}$ \\
\hline Transponder & $3897 \mathrm{H} 3000$ \\
\hline Frekuensi & $3897 \mathrm{MHz}$ \\
\hline Simbol Rate & $3000 \mathrm{kSps} / \mathrm{kHz}$ \\
\hline Polarisasi & Horisontal
\end{tabular}

Channel MTA TV adalah saluran televisi yang menyiarkan program acara

\footnotetext{
${ }^{14}$ https://www.wajanterbang.com/2019/08/freku ensi-mta-tv.html, diakses 25 Juni 2021

${ }^{15}$ http://mtatv.net/v2/, diakses 25 Juni 2021
} 
dakwah Islam, hiburan, talkshow, kesehatan, berita, pendidikan dan lain lain. Setiap hari Minggu MTA pusat selalu rutin mengadakan pengajian dan MTA TV menyiarkan pengajian tersebut yang dikenal dengan program Jihad Pagi.

Seiring berkembangnya zaman, MTA TV juga dapat diikuti melalui beberapa situs website

- mtatv.net/v2

- useetv.com/livetv/mtatv, melalui website ini tayangan MTA TV dalam rentang tujuh hari ke belakang masih bisa dinikmati tanpa harus berlangganan terlebih dah ulu.

- youtube.com/user/OfficialMTATV, di situs ini sering menayangkan live streaming dan juga ada video singkat berisi highlight berita yang terjadi akhir-akhir ini.

Keberadaan MTA TV tidak bisa dilepaskan dari yayasan MTA secara keseluruhan, karena MTA TV merupakan salah satu wasilah dakwah yang dimiliki yayasan tersebut. Oleh karena itu, tujuan MTA TV pada akhirnya tidak akan jauh dari tujuan MTA itu sendiri, yakni mengajak umat Islam kembali kepada AIQur'an.

Tagline MTA TV Channel terpilih merupakan sebuah harapan lembaga bahwa program yang disajikan adalah program-program unggulan yang akan menjadi salah satu tujuan atau pilihan umat Islam dalam menonton televisi.

\section{Lingkungan Strategis MTA TV}

\footnotetext{
${ }^{16}$ M. Munir dan Wahyu Ilahi, Manajemen Dakwah, (Jakarta: Prenada Media. 2006), hal. 135.
}

Pada tataran aplikasi seringkali organisasi dakwah akan menghadapi kondisi ketidakpastian lingkungan. Oleh karenanya, salah satu cara untuk mengantisipasi kondisi tersebut adalah melalui penyesuaian dalam struktur. ${ }^{16}$ Mengetahui faktor internal dan faktor eksternal pengelolaan MTA TV merupakan salah satu upaya untuk menentukan strategi pengembangan dakwah MTA melalui televise tersebut.

a. Kondisi Internal Pengelolaan MTA TV

MTA TV mempunyai sumber daya manusia (SDM) yang profesional dan berdedikasi tinggi pada pekerjaan serta struktur penyiaran yang jelas. Selain itu, MTA TV mempunyai peralatan yang canggih dan memadai untuk melakukan siaran seperti halnya stasiun televisi lain. Mereka memanfaatkan kecanggihan teknologi untuk mendapatkan informasi yang lebih tepat dalam mengambil keputusan yang lebih cepat untuk mengatasi permasalah yang terjadi pada mad'u (pendengar). Jangkauan siar MTA TV ini sangat luas, terlabih saat ini siaran bisa ditembus melalui internet live streaming, melalui youtube dan media sosial lainnya.

Dalam masalah pendanaan, MTA TV bergantung sepenuhnya dari yayasan MTA. Format dan jadwal acara yang disajikan MTA TV sudah tersusun dengan rapi. Menu acara setiap hari dan minggu beragam, variasi program antara lain berita, talk show, dan hiburan. Acara yang 
disajikan setiap hari adalah Murotal, Kamus On Air, Tausiyah Pagi, Bunga Rampai, Lembar Ilmu, Fajar Hidayah mulai pukul 00.00 sampai 06.00 WIB. Setalah pukul 06.00 sampai pukul 00.00 acara beragam setiap harinya, misalnya Acara Aku Bisa dan Khazanah, MTA Highlight, Lembar Ilmu. Mitra Tani, Gareng Mudheng, Risalah Tafsir, Dunia Pendidikan, Tahsin, Hikmah, Risalah Hadits, Prestasi, Kilau Ananda, Gurit Macapat, dan lain sebagainya. ,

b. Kondisi Eksternal Pengelolaan MTA TV

Surakarta, juga disebut Solo adalah wilayah otonom dengan status kota di bawah provinsi Jawa Tengah. Kota dengan luas $44,04 \mathrm{~km}^{2}$ ini berbatasan dengan Kabupaten Karanganyar dan Kabupaten Boyolali di sebelah utara, di sebelah timur dan barat berbatasan dengan Kabupaten Karanganyar dan Kabupaten Sukoharjo, dan Kabupaten Sukoharjo juga di sebelah selatan..

MTA TV berada di tengah-tengah kota Surakarta yang sangat heterogen masyarakatnya. Sebagai sebuah gerakan pemurnian agama Islam, MTA dihadapkan setting masyarakat yang tidak vakum dan steril. Masyarakat yang memiliki ragam corak keadaan dengan berbagai persoalannya, masyarakat yang ragam nilai serta majemuk dalam tata kehidupan, masyarakat yang sering mengalami perubahan secara cepat, yang mengarah pada masyarakat fungsional, masyarakat saintifik, dan masyarakat terbuka. Dari segi politik praktis, masyarakat kota Surakarta tidak terpancang hanya pada salah satu partai nasional.

Keadaan mata pencaharian penduduk suatu daerah dipengaruhi oleh sumber daya yang tersedia dan kondisi sosial ekonomi seperti ketrampilan yang dimiliki, tingkat pendidikan, lapangan pekerjaan dan modal yang ada. Mata pencaharian penduduk Kota Surakarta cukup beragam. Sebagian penduduk Kota Surakarta bermata pencaharian dalam sektor jasa, pedagang dan pegawai pemerintahan.

c. Posisi MTA TV

Keberadaan MTA TV sebagai televisi satelit masih dan akan bertahan sebagai sarana komunikasi massa yang berisi pesan-pesan Islam terpenting di tengah banjirnya informasi di internet saat ini. Terlebih MTA TV juga sudah mengudara melalui live streaming youtube dan useetv.com. Selain itu, beberapa program MTA TV juga seringkali ditayangkan melalui akun facebook mtatvofficial dan akun instagram @)mtatv official.

MTA TV berada pada kondisi lingkungan yang tidak begitu pasti, meskipun sumber daya manusia yang melimpah, peralatan yang memadai, dan mempunyai jaringan yang luas. Namun, permasalahan yang terjadi pada mad'u atau pemirsa televisi semakin kompleks. Permasalahan lain yang dihadapi adalah benturan dengan beberapa masyarakat yang menganggap materi siaran dakwah 
seringkali menimbulkan keresahan di sebagian pihak.

\section{Strategi Dakwah MTA TV}

Dalam upaya pengembangan dakwah, strategi yang digunakan MTA TV selama ini lebih menekankan pada pengelolaan redaksi dan perluasan jangkauan siaran.

Pertama, pengembangan dakwah secara redaksional yaitu dengan cara menyiarkan materi keislaman yang meliputi akidah, syariah, dan akhlah yang ada dalam Islam sesuai dengan $\mathrm{Al}$ Qur'an dan Hadits berdasarkan hasil kajian MTA, juga menyiarkan ilmu yang bermanfaat lain, seperti ekonomi, bisnis, dan pertanian.

Dalam implementasinya, MTA TV menyampaikan pesan dakwahnya dengan dua cara, yaitu:

1) Menyiarkan program khusus dakwah, seperti pengajian ahad pagi (Jihad Pagi), Kajian Tafsir dan Hadits, Tahsin, Tausyiah Pagi, Lembar Ilmu, Fajar Hidayah, Tabligh, Kajian Jelas, Meniti Jalan Dakwah.

2) Menyisipkan pesan-pesan dakwah dalam acara yang lain. Metode ini dilakukan dengan menyisipkan nilai ajaran Islam melalui tampilan acara umum dalam format talk ataupun hiburan yang secara substansial ditujukan untuk memberi manfaat bagi pemirsa televisi. Misalnya acara Plesiran, Mitra Tani, Saatnya Wisata Boga, Si Sopan-Sobat Pandai, Gareng Mudheng, Kilau Ananda.
Untuk dapat bertahan menghadapi persaingan, MTA TV sangat menekankan fleksibilitas dan inovasi. Oleh karena itu, MTA TV sangat jeli memandang media lain. Ketika di media lain ada program acara yang berbeda, maka MTA TV mengambil celah. MTA TV akan melakukan counter acara tersebut jika diperlukan. Bahkan akan mengadopsinya kalau dipandang efektif dalam penyampaian pesan.

Pada dasarnya semua acara yang ada di MTA TV mempunyai pemirsa. Walaupun segmentasi televisi ini umum, namun televisi ini lebih banyak ditonton oleh orang-orang yang tergabung dalam komunitas MTA, yang ingin mencoba melaksanakan Al Qur'an dan Sunnah, dan juga mereka ingin menjaga diri dari hal-hal yang mudharat.

Acara yang menjadi unggulan di semua media massa MTA yaitu pengajian ahad pagi yang dilakukan secara on air maupun off air. Acara ini dipancarkan secara luas melalui satelit, internet live streaming, dan juga radio MTA FM dan radio Persada 102,2 FM. Pengajian ini awalnya diampu langsung oleh ketua umum MTA Pusat yakni ustadz Ahmad Sukino. Pengajian ahad pagi merupakan sebuah acara yang menggunakan perpaduan format monolog dan dialog.

Kedua, perluasan jangkauan siaran. MTA TV dipancarkan melalui Satelit Telkom 4 dengan frekuensi $3896 \mathrm{Mhz}$, simbol rate $3000 \mathrm{Ksps}$ dan polarisasi horizontal 108 bujur timur. MTA TV memanfaatkan live streaming youtube, facebook, dan juga instagram. 
Gambar 1. Sosial Media MTA TV

\section{Konsistensi untuk Mencapai Tujuan} MTA melalui MTA TV

Melihat tujuan dakwah MTA melalui MTA TV, penulis mencoba untuk merumuskan konsistensi dalam pencapaian tujuan dengan tabel value chain di bawah ini

Tabel 2.VALUE CHAIN

\begin{tabular}{|c|c|c|c|c|}
\hline \multicolumn{5}{|c|}{ PRIMARY ACTIVITIES } \\
\hline \multirow{7}{*}{ 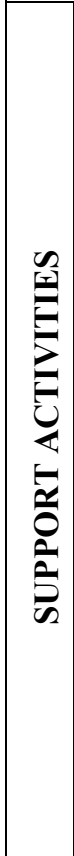 } & & $\begin{array}{l}\text { Pere } \\
\text { ncan } \\
\text { aan }\end{array}$ & Dakwah & $\begin{array}{c}\text { Pasca } \\
\text { Dakwa } \\
\text { h }\end{array}$ \\
\hline & $\begin{array}{l}\text { Organisa } \\
\text { si }\end{array}$ & Ada & Baik & Baik \\
\hline & $\begin{array}{l}\text { Prasaran } \\
\text { a dan } \\
\text { Sarana }\end{array}$ & Ada & Baik & Baik \\
\hline & SDM & Ada & Cukup & $\begin{array}{l}\text { Kurang } \\
\text { Maksi } \\
\text { mal }\end{array}$ \\
\hline & Finansial & Ada & Cukup & Cukup \\
\hline & Sistem & Ada & Cukup & Cukup \\
\hline & SIM & Ada & $\begin{array}{l}\text { Kurang } \\
\text { maksimal }\end{array}$ & $\begin{array}{l}\text { Kurang } \\
\text { Maksi } \\
\text { mal }\end{array}$ \\
\hline
\end{tabular}

Dari tabel di atas dapat dijelaskan bahwa dalam setiap kegiatan MTA TV mempunyai perencanaan yang baik, akan tetapi dalam proses dakwahnya terjadi banyak kekurangan sehingga belum bisa mencapai hasil yang maksimal sesuai yang diharapkan. Dalam pembuatan rencana pelaksanaan misi dakwah belum bisa dalam tahapan yang realistis dengan pengukuran kualitas yang berkesinambungan. Dari sisi sumber daya manusia terlihat adanya ketidakkonsistenan karena pasca dakwah tidak ada peningkatan yang signifikan setelah melihat berbagai tayangan yang disajikan MTA TV. Sarana dan prasarana yang memadai untuk siaran televisi terkelola dengan baik dan tentunya turut mendukung pencapaian visi dan misi MTA pada umumnya. Sedangkan dari segi finansial cukup karena dana menggantungkan dari organisasi induknya yaitu MTA, para donator dan juga iklan di youtube.

Arah utama tujuan MTA adalah bersifat eksternal, berfokus pada kebutuhan khalayak penonton televisi dan secara tipikal menspesifikasikan pada usaha tertentu yang akan dilakukan MTA TV dalam mencapai tujuan dakwahnya dengan berbagai program dakwah baik yang secara implisit maupun eksplisit.

\section{Lingkungan Strategis (Kondisi Internal dan Eksternal)}

Kelebihan dakwah melalui televisi terletak pada efektifitas dan efisien berdakwah, didukung pula dengan pemanfatan internet. Hal ini nampak dari adanya bentuk yang sederhana tanpa harus bertemu dan bertatap muka langsung antara da'i dan mad'unya. Televisi dapat menjangkau mad'unya dalam jarak jauh dan meluas. Oleh karena itu, televisi merupakan media yang efektif dalam penyampaian dakwah untuk semua kalangan.

\section{Faktor Internal}

Faktor internal sebuah organisasi adalah kemampuan internal dan kondisi sumber daya organisasi yang meliputi sumber daya manusia dan 
sarana prasarana organisasi serta tujuan yang akan dicapai.

1) Kekuatan

a. Memiliki sumber daya manusia yang profesional dan berdedikasi tinggi pada pekerjaan.

b. Memiliki fasilitas, sarana, dan peralatan yang bagus juga memadai sebagaimana studio televisi pada umumnya.

c. Memiliki jaringan satelit di Telkom 4 dan di useetv.com yang program acara sepekan lalu masih bisa ditonton

d. Memiliki subcriber youtube dan jejaring sosial yang banyak pengikutnya.

2) Kelemahan

a. Pola perencanaan dan manajemen yang belum mantap.

b. Lemahnya promosi dan iklan.

c. Pendanaan yang belum terlalu mencukupi.

d. Kurang memahami kondisi mad'u yang dihadapi.

e. Kurangnya variasi program

Faktor Eksternal

Faktor eksternal merupakan kondisi lingkungan di luar organisasi yang sangat berpengaruh dalam penyusunan strategi. Terminologi 'lingkungan' tidak semata-mata merefleksikan lingkungan ekologi, tetapi juga konsep umum yang menjelaskan gambaran keseluruhan terhadap kekuatan lingkungan eksternal organisasi. Hal tersebut dapat berdampak pada aktivitas organisasi dari berbagai aspek. ${ }^{17}$

1) Peluang

a. Pertumbuhan umat Islam yang semakin besar.

b. Kecanggihan teknologi yang semakin berkembang.

c. Kerjasama dengan stasiun televisi lokal yang ada di Surakarta maupun nasional.

2) Tantangan

a. Persaingan dengan televisi digital ataupun kabel dan media lain yang lebih canggih

b. Benturan dengan pemerintah karena materi siarannya.

c. Perubahan selera dan kebutuhan khalayak.

d. Perbedaan pandangan dalam masyarakat.

e. Anggapan negatif masyarakat terhadap organisasi MTA.

Posisi

MTA TV mempunyai posisi yang tidak begitu strategis, karena sebagian masyarakat beranggapan bahwa beberapa siarannya terlalu keras, terkadang membentur ajaran-ajaran Islam yang sangat peka atau sensitif. Meskipun sudah banyak variasi program acara yang ditawarkan seperti acara-acara hiburan. Pada gambaran tabel ETOP berikut ini, posisi MTA akan

17 Mudrajad Kuncoro, Strategi (Bagaimana Meraih Keunggulan Kompetitif). (Jakarta: Erlangga. 2005), hal. 21. 
ditunjukkan dengan tabel yang berwarna gelap.

Table 3. Environment Threats-Opportunity Profiles (ETOP)

\begin{tabular}{cccc}
\multicolumn{1}{c}{} & & \multicolumn{2}{c}{ Opportunity } \\
\cline { 3 - 3 } & & Besar & Kecil \\
\cline { 3 - 4 } Risk & Besar & Spekulatif & Avoid \\
\cline { 3 - 4 } & & & \\
\cline { 3 - 4 } & Kecil & Ideal & Nature \\
\cline { 3 - 4 } & & &
\end{tabular}

\section{Kesimpulan}

Berdasarkan pembahasan di atas dapat disimpulkan bahwa strategi yang digunakan oleh MTA TV adalah sebagai berikut:

1. Menggunakan strategi adaptif dalam penyusunan program siaran, MTA TV sangat memperhatikan inovasi dan adaptasi terhadap kemajuan zaman

2. Melakukan deferensiasi dengan membuat program yang berbeda dari yang lain, misalnya dengan menyajikan acara unggulan "Jihad Pagi" dan berani dalam menyampaikan pesan dakwah, baik secara eksplisit maupun implisit.

3. Melakukan perluasan jangkauan siaran dengan memanfaatkan situs jejaring sosial yang sedang ramai disukai banyak orang.

Berdasarkan pembahasan tersebut di atas hendaknya MTA TV lebih kreatif dalam membuat variasi program baik dari segi bahasa yang digunakan atau materi yang disampaikan, sehingga tidak terkesan monoton dan membosankan pendengarnya. Untuk meminimal friksi di masyarakat hendaknya MTA TV lebih selektif dalam memilih materi pesan dakwah. MTA TV hendaknya juga membuat segmentasi yang lebih jelas dan spesifik, misalnya berdasarkan kelompok umur, status sosial, pekerjaan dan sebagainya, sehingga pesan dakwah bisa disesuaikan dengan kebutuhan penonton.

\section{Daftar Pustaka}

Dermawan, Andy. Manajemen Dakwah Kontemporer Di Kawasan Perkampungan (Studi Pada Kelompok Pengajian Asmaul Husna, Potorono, Banguntapan, Bantul, DIY), (Jurnal MD, Edisi Januari-Juni 2016)

Effendi, Onong Uchjana. 2006. Ilmu Komunikasi Teori Dan Praktek. Bandung: PT. Remaja Rosdakarya.

Ismail, Faisal. Dakwah Ditengah Persoalan Budaya dan Politik. Jakarta: Kurnia Kalam Semesta. 2001

Kuncoro, Mudrajad. Strategi (Bagaimana Meraih Keunggulan Kompetitif). Jakarta : Erlangga. 2005

Moleong, Lexy. Metodologi Penelitian Kuliatatif. Bandung: Remaja Rosdakarya, 2010

Muhiddin, Asep. Dakwah dalam Perspektif Al-Qur'an, Cet. I. Bandung: Pustaka Setia, 2002 
Munir, Muhammad dan Wahyu Ilaihi. Manajemen Dakwah, Jakarta: Prenada Media. 2006

Olii, Helena. Reportase Radio. Jakarta: Indeks Kelompok Gramedia. 2006

Shaleh, A. Rosyad. Manajemen Dakwah Islam. Jakarta: Bulan Bintang, 1993

Suparta, Munzier dan Harjani Hefni. Metode Dakwah. Jakarta: Prenada Media. 2003

Ulfah, Novi Maria. Strategi dan Manajemen Dakwah Lembaga Dakwah Islam Indonesia (LDII) Kecamtan Tugu Kota Semarang, (Jurnal Ilmu Dakwah, Vol 35, No 2, 2015) 